\title{
Development of System Rice Intensification (SRI) paddy transplanter
}

\begin{abstract}
The System of Rice Intensification (SRI) practices have been developed in order to increase the production and quality of rice. Based on SRI practices the rice seedlings are transplanted at the young ages, 15 days old with just 2 leaves and carefully planting of just one seedling per hill and space the hills optimally widely in a square pattern of $25 \times 25 \mathrm{~cm}$ for better usage of water, sunlight, minerals, space, nutrient, weeding and pest management within shallow depth $(1-2 \mathrm{~cm})$ in the moist soil condition. The existing method of mechanical transplanting of paddy which planted between 5 and 8 seedlings per stand is claimed to be inefficient to produce higher yield. From the survey that was carried out, most farmers are looking forward to single-planting translators as it is impossible to do it manually. Modifications have to be carried out on the planting claw (kuku kambing) so that it will only catch one seedling at a time, redesign the seedling tray to allow the SRI transplanter to catch one seedling at a time and determine the best soil condition suitable for the SRI practices. No doubt that the new develop transplanter for SRI will be the future machines for the farmers in Malaysia. Evidence have shown that the SRI practices in paddy cultivation has resulted in the increase in yield as well as superior quality paddy because of its shorter crop cycle, less need for seeds and fertilizer, less chaffy grain because of higher percentage grain filling, little or no lodging from wind or rain and higher head rice recovery rate, so more milled rice from a given amount of paddy and reduced labour demand while boosting productivity. The most important factors that influence the performance are soil moisture content, system of raising seedlings in nursery, degree of land labelling and finally the size of planting claw.
\end{abstract}

Keyword: Age of seedling transplanting; Nursery management; Rice cultivation; System of rice intensification; Translator 